TITLE:

Physiological and biological predictors of length of stay and recovery in adults with acute asthma: an observational cohort study

RUNNING TITLE:

Factors affecting length of stay in asthma

AUTHORS:

Thomas L Jones1,2 - analysed data, drafted and revised the paper

Jonathon Owen2,3 - designed and performed the study and revised the paper

Scott Elliott1,2 - performed analysis and revised the paper

Thomas Brown1,2 - designed and performed the study and revised the paper

Dominic Reynish1,2 - performed the study and revised the paper

Heena Mistry1 - performed the study and revised the paper

Sumita Kerley1 - performed the study and revised the paper

Salah Matti3 - performed the study and revised the paper

Janis K Shute2 - designed and performed the study and revised the paper

Anoop J Chauhan1,2, - designed and performed the study and revised the paper

1 -Portsmouth Hospitals NHS Trust, Portsmouth, UK

2 -University of Portsmouth, Portsmouth UK

3-Hampshire Hospitals NHS Foundation Trust

4 - Western Sussex Hospitals NHS Foundation Trust,

CORRESPONDING AUTHOR:

Dr Thomas Jones,

Department of Respiratory Medicine, Queen Alexandra Hospital, Portsmouth, England, PO6 3LY

Tom.jones@doctors.org.uk

(+44) 2392286000 ext. 4108

\title{
DISCLOSURE STATEMENT:
}

Dr Jones, Dr Owen, Mr Elliott, Dr Brown, Dr Reynish, Dr Mistry, Ms Kerley, Dr Matti, Prof Shute and Prof Chauhan report no conflict of interest. This study was supported by a grant from Asthma UK.

This article has been accepted for publication and undergone full peer review but has not been through the copyediting, typesetting, pagination and proofreading process which may lead to differences between this version and the Version of Record. Please cite this article as an 'Accepted Article', doi: 10.1111/crj.12516 


\section{ABSTRACT}

Introduction: Asthma is a prevalent, chronic disease associated with significant risk to patients and cost to healthcare systems. Accurate estimates of length of stay and recovery are important for patient information, physician prognostication and management of inpatient beds.

Objectives: To assess factors affecting length of stay and time to recovery in adults with acute asthma.

Methods: We prospectively recruited adult asthmatic non-smokers admitted with an asthma exacerbation. Participants were assessed for demographics, symptoms, medications, bloods including blood count, clotting status and cytokines. Results were analysed for correlation and subsequently in a regression model.

Results: 126 participants were recruited of which $75.4 \%$ were female. Mean age was 40.0 and mean length of stay 3.98 days. Length of stay was associated with lower APTT ratio $(<p=0.001)$, oxygen requirement $(p=0.02)$, increased AST $(p=0.005)$, increasing age $(p=0.02)$ and lower \%predicted FEV1 $(p=0.02)$. Longer time to recovery was associated with plasma IL-12 $>1 \mathrm{pg} / \mathrm{mL}(\mathrm{p}=0.04)$.

Conclusion: Older participants with lower FEV1 and supplemental oxygen requirements are likely to remain in hospital longer. Activation of the "intrinsic" clotting pathway correlates with an increased length of stay as does a raised serum AST. Detectable IL-12 in plasma correlates with slower recovery and this may be due to poor response to corticosteroids.

MeSH terms: Asthma, Length of Stay, Hospitalization, Cytokines, Inpatients, Interleukin-12

\section{INTRODUCTION:}

Asthma is a prevalent, chronic inflammatory condition of the airways causing airway hyperresponsiveness, wheeze and cough and affecting around 300 million people worldwide [1]. Asthma is becoming more common[2], and was the $28^{\text {th }}$ most common cause of loss of disability adjusted life-years (DALYs) worldwide in 2010 [3] with fatality rates of up to 35 per 100,000 asthmatics. Asthma affects around 5.4 million people in the UK (16\% of the population) $[1,4]$ and many of these remain poorly controlled on maximal medical therapy. Asthma is a worldwide threat, leading to deaths worldwide including 3,345 asthma deaths reported in US in 2011[5] and around 1000 people per year die of asthma in the UK [4], representing annual death rates of 1 in 93,000 and 64,000 respectively. It is therefore vital that we better understand the biology underlying exacerbations.

The prevalence and potential risk of asthma equate to a large cost to health care systems. The UK National Health Service (NHS) spends around $f 1$ billion per year $[6,7]$ caring for people with asthma, with $80 \%$ of this spent on the most severe $20 \%$ of patients. There were 65,316 hospital admissions with asthma in the UK in 2011-12 [4] representing a significant burden to the NHS. Length of stay, the duration of a patient's inpatient admission to hospital, is an important metric of clinical care but also of high importance to those planning healthcare resources. Understanding the likely period a patient will require a hospital bed is relevant to the patient in terms of planning discharge but also to those monitoring bed availability and requirements within a pressurised healthcare system. 
The coagulation system has been strongly implicated in the pathogenesis of asthma [8] with platelet activation [9,10], platelet dependant eosinophil migration [11] and a fibrinogenic [12] or fibrinolytic [13] intra-bronchial environment depending on disease severity.

Previous work on length of stay of persons with asthma is mostly confined to the paediatric population [14,15] or critical care units [16], and therefore cannot be easily applied to adult admissions. A large retrospective cohort analysis of 56,768 admissions [17] predominantly discussed temporal and demographic characteristics but we could not find previous work examining biochemical and physiological influences on length of stay. We conducted a study aiming to assess factors affecting length of stay and time to recovery in people admitted with acute asthma.

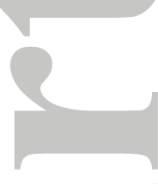

\section{MATERIALS AND METHODS:}

\section{Participants}

Over a 15 month period we prospectively recruited $18-70$ year old participants with asthma diagnosed at least 1 year previously who were admitted to hospital with an acute exacerbation of asthma. Participants were recruited from 2 UK sites (Portsmouth Hospitals NHS Trust (PHT) and Basingstoke and North Hampshire NHS Foundation Trust (BNHFT)) from the Accident and Emergency department, Medical Assessment Unit or wards. Participants were identified by daily computer searches of the above clinical areas (PHT, $n=122)$ or by referral to site researchers (BNHFT, $n=3$ ). Current smokers and ex-smokers with a pack year history of 20 or more were excluded due to the impact of smoking on cytokine levels. Other exclusion criteria were significant cardiopulmonary comorbidities, clinically significant neurological, renal, endocrine, gastrointestinal, hepatic or haematological abnormalities uncontrolled with standard treatment, pregnant women, long-term anticoagulants or bleeding diatheses, alcohol and drug abuse, immunomodulatory therapy, significantly abnormal chest X-ray or those in interventional research studies. Participants later found to have an acute diagnosis other than an exacerbation of asthma were withdrawn.

\section{Study design}

In this prospective study, participants were assessed on admission for demographic data, medical history and medications, symptoms and observations, blood tests, spirometry (Microlab 3500 (Carefusion, Hampshire, UK) or Vitalograph Alpha Touch (Vitalograph, Buckinghamshire, UK)) and fractional exhaled nitric oxide (NIOX MINO, Aerocrine, Solna, Sweden). Participants remained under the care of their own clinicians. Participants were discharged when they did not require supplemental oxygen, intravenous medication or nebulised bronchodilators and their peak flow had recovered to at least $75 \%$ of their normal. In view of a lack of standardised definition of recovery from acute exacerbation, participants were asked if they felt they had recovered to baseline at 4 weekly intervals after discharge.

\section{Blood tests}


Bloods tests performed included full blood count with cell differential, INR and APTT ratio, D-dimer, fibrinogen, CRP, IgE, liver function tests, urea and electrolytes.

Multiplex cytokine analysis (IL-5, IL-6, IL-8, IL-12, IL-13, IL-17A, IFN- $\gamma$, TNF- $\alpha$, RANTES, eotaxin) was performed on blood from the first 61 participants using immunofluorescence with the commercially available Millipore ${ }^{\mathrm{TM}}$ Milliplex@ Map Human cytokine/chemokine kit (Millipore Corp, Missouri, USA) according to the manufacturers' instructions and read using Luminex $200^{\mathrm{TM}}$ analyser (Luminex corporation, Texas, USA).

\section{Statistical Analysis}

Statistical analysis was performed and Pearson product moment correlation coefficients were used to look for key demographic, clinical or biochemical factors affecting length of stay and time to recovery. Further analysis was performed on factors demonstrating significant correlation using linear regression. Univariable and multivariable analyses were performed using a backward selection model with length of stay or time to recovery as the outcome variable. Time to recovery was analysed using survival analysis giving hazard ratios for recovery as it was expected that not all patients would report recovery within follow up. Nonlinear relationships were modelled using polynomial terms. Factors that were not correlated with length of stay or time to recovery were not included in regression models. T-tests were used to compare age and length of stay of those who withdrew relative to the remaining sample, and to compare IL-12 concentration in those with and without family history of asthma. Statistical analyses were conducted using Stata v12.1 (StataCorp, Texas, USA) and Excel 2010 (Microsoft Corp, Washington, USA).

Ethics approval was granted by Berkshire Research Ethics Committee (REC) on 12th August 2010 (REC reference 10/H0505/59).

\section{RESULTS}

Data were collected on the acute admissions of 125 participants, 94 female and 31 male with a mean age of 40.0 years and a mean length of stay of 3.98 days. Demographics are shown in Table 1. Two hundred and fourteen participants were screened, 87 participants failed screening and 29 participants were withdrawn prior to completing the study: 20 withdrew through failure to attend follow-up, 1 participant was shown to have pneumonia in addition to an exacerbation of asthma, 1 started on anti-IgE therapy prior to follow-up, 1 admitted to a higher smoking history following enrolment, 1 had another exacerbation prior to follow-up and 5 participants withdrew themselves.

Length of stay was examined using univariable regression analysis (table 2) and significant increases in length of stay were identified with increasing age $(p=0.003$, figure 1$)$, oxygen requirement on admission $(p=0.009)$, aspartate transaminase $(p=0.04$, figure 2$)$, participant-reported wheeze $(p=0.006)$ and a decrease in APTT ratio ( $p=0.003$, figure 3$)$, FEV1 $(p=0.005)$ and FVC $(p=0.02)$. Significant correlation was not found for other factors described in the methods section. Aspartate transaminase concentrations were not significantly different between those given antibiotics prior to admission and those without $(p=0.87)$. Participants who withdrew were not significantly different from the rest of the population in terms of length of stay (two tailed t test $p=0.33$ ) but were significantly younger (mean 32.7 vs $41.9, p=0.001$ ). 
Possible factors affecting length of stay $(p<0.2)$ identified with univariable regression were further examined with multivariable regression (table 3 ) and wheeze symptoms were found to no longer be associated while the most significant association was with a decreased APTT ratio $(p=<0.001)$ as shown in figure 3 . Length of stay did not vary significantly between groups receiving LMWH as inpatient thromboprophylaxis prior to phlebotomy and those not receiving LMWH $(p=0.44)$.

Time to recovery was analysed using survival methods as not all participants recovered. Univariable analysis (table 4) showed family history of asthma and admission plasma IL-12 concentrations were significantly associated with delayed recovery. A positive family history gave a hazard ratio of 0.49 for recovery at any given time-point $(95 \% \mathrm{Cl} 0.30-0.80, \mathrm{p}=0.005)$. A detectable plasma IL-12 concentration $(>1 \mathrm{pg} / \mathrm{mL})$ gave a hazard ratio of 0.44-0.52 ( $p=0.04)$. Family history became nonsignificant in multivariable regression, leaving admission plasma IL-12 concentration as the only consistent predictor of delayed recovery. IL-12 was not significantly different between groups with positive and negative family history $(p=0.92)$. Length of stay did not significantly affect time to participant reported recovery.

\section{DISCUSSION}

These results show that activation of the intrinsic clotting pathway as measured by a drop in the APTT correlates with length of stay and may be a useful biochemical addition to standard measures of exacerbation severity. Figure 3 demonstrates that the majority of variation in APTT ratio occurs within the normal range of 0.8-1.2. This is the first time that APTT has been linked to length of stay in asthma, and this may reflect activation of the intrinsic clotting system by activated platelets. It is recognised that platelet activation occurs during exacerbations of asthma [8-10], and activated platelets potentiate activation of factor XII and factor XI [18]. A reduced APTT has been shown to be associated with activation of the clotting system [19]. The APTT may therefore be a marker of the severity of the inflammation within the airways, and that a drop in APTT ratio may represent a more severe exacerbation. This said, D-dimer concentration did not correlate with length of stay and this may be because of increased plasminogen activator inhibitor (PAI-1) and thrombin-activatable fibrinolysis inhibitor (TAFI) concentrations that have been demonstrated in severe asthma [11]. Previous work within our group has shown activation of the extrinsic clotting system within the airways of people with severe asthma [11], mediated by plasma leak and exposed tissue factor and leading to intra-bronchial fibrin formation. Majoor et al demonstrated airway and systemic procoagulant activity in people with asthma following experimental rhinovirus 16 infection [20], and it is possible that our findings indicate a viral aetiology for our participants' exacerbations.

Our data show an increase in aspartate transaminase (AST) correlates significantly with an increased length of stay (figure 2), and this has previously been recognised [21]. El-Shaboury et al reported a series of cases in the BMJ in 1964 demonstrating increases in serum transaminase in 40\% of persons admitted with acute asthma. This does not seem to have been an effect of myocardial infarction or glucocorticoid therapy. Suggested explanations included hepatic hypoxia, hepatic venous congestion and cardiac strain secondary to increased pulmonary resistances but work in this area does not appear to have progressed. The variation in length of stay with age is demonstrated in Figure 1 , showing a nadir around age 35, escalating either side of this. This likely reflects co-morbidity and clinical caution rather than being a function of severity of asthma in these participants. Our data do 
not demonstrate association between length of stay and a number of factors that might be expected to be associated. Severity of asthma, as estimated by inhaled corticosteroid dose, was not associated with length of stay (table 1), nor was a delay between symptoms onset and attendance.

Survival analysis showed that participants with detectable levels of plasma IL-12 (>1pg/mL) had a significantly delayed self-reported recovery $(p=0.04)$, although this is not corrected for multiple analysis. Univariable regression showed a significant link between family history and time to recovery although this did not remain significant in multivariable analysis despite a lack of correlation between the two factors. The correlation between plasma IL-12 concentration, indicative of a Th1 differentiation stimulus [22] from macrophages, B-cell precursors and dendritic cells, and delayed recovery may be due to reduced corticosteroid responsiveness [23]. The association of plasma IL-12 with delayed recovery would benefit from confirmation in a further cohort as the significance level of the association was borderline.

\section{Study limitations}

This study is the first to look at the effect of biochemical indices including cytokine concentration on length of stay and recovery, linking these currently academic considerations with clinically relevant outcomes. Recruitment was not powered to detect differences in length of stay, so other factors may become significant in a larger cohort. The younger age of participants who withdrew from the study may have introduced an element of bias into the analysis, although their length of stay was similar to the remaining participants. Participants were asked when they first started experiencing symptoms of their exacerbation to determine whether a delay in presentation resulted in a prolonged admission and this was not seen but this data was subject to recall bias. Cytokine measurement was limited to 61 participants due to prioritisation of samples for clinical testing and limited opportunity to return to repeat sampling. Several participants were unable to complete spirometry on admission. We do not believe further samples or testing would have changed our results as few other analyses were approaching significance.

Current smokers or ex-smokers of 20 or more pack years were excluded from this study in order to avoid confounding due to COPD and the impact on smoking on study measurements. These results may be important for smokers however, as smokers have been shown to have a lower APTT and hypercoagulable platelets [24]. The impact of the coagulation system on the interaction between smoking and asthma has not been described.

\section{Further work}

These data could be used to develop a model for estimated length of stay in people with acute asthma. Further work to elucidate the role of the intrinsic clotting pathway in the pathogenesis of asthma and the cause of raised serum transaminases is needed, both for prognostication and elucidation of therapeutic targets.

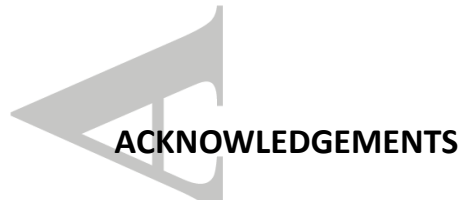

Thanks to Paul Bassett (Statsconsultancy Ltd, UK) for statistical analysis. 
FUNDING

Funding was received from Asthma UK (Reference number 10/074)

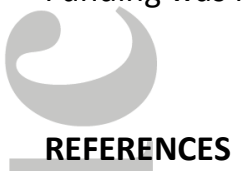

[1] GINA. Global burden of asthma report. http://www.ginasthma.org/Global-Burden-ofAsthma . Last accessed 10/06/2015.

[2] Akinbami L, Moorman JE, Bailey C, Zahran HS, King M, Johnson C a, Liu X. Trends in asthma prevalence, health care use, and mortality in the United States, 2001-2010. NCHS Data Brief [Internet] 2012; : 1-8

[3] Murray CJL, Vos T, Lozano R, Naghavi M, Flaxman AD, Michaud C, Ezzati M, Shibuya K, Salomon JA, Abdalla S, Aboyans V, Abraham J, Ackerman I, Aggarwal R, Ahn SY, Ali MK, Alvarado M, Anderson HR, Anderson LM, Andrews KG, Atkinson C, Baddour LM, Bahalim AN, Barker-Collo S, Barrero LH, Bartels DH, Bas????ez MG, Baxter A, Bell ML, Benjamin EJ, et al. Disability-adjusted life years (DALYs) for 291 diseases and injuries in 21 regions, 1990-2010: A systematic analysis for the Global Burden of Disease Study 2010. Lancet 2012; 380: 21972223.

[4] Royal College of Physicians. National review of asthma deaths. https://www.rcplondon.ac.uk/projects/national-review-asthma-deaths Last updated 05/12/2014. Last accessed 10/06/2015.

[5] CDC. National Vital Statistics Report (NVSR) "Deaths: Final Data for 2011". http://www.cdc.gov/nchs/products/nvsr.htm

[6] Asthma UK facts and statistics. http://www.asthma.org.uk/asthma-facts-and-statistics

[7] An Outcomes Strategy for COPD and Asthma: NHS Companion Document. https://www.gov.uk/government/publications/an-outcomes-strategy-for-people-withchronic-obstructive-pulmonary-disease-copd-and-asthma-in-england

[8] Wagers SS, Norton RJ, Rinaldi LM, Bates JH, Sobel BE, Irvin CG. Extravascular fibrin, plasminogen activator, plasminogen activator inhibitors, and airway hyperresponsiveness. J Clin Invest. 2004 Jul 1; 114(1): 104-111.

[9] Moritani C, Ishioka S, Haruta Y, Kambe M, Yamakido M. Activation of platelets in bronchial asthma. Chest. 1998 Feb;113(2):452-8.

[10]Benton AS, Kumar N, Lerner J, Wiles AA, Foerster M, Teach SJ, Freishtat RJ. Airway platelet activation is associated with airway eosinophilic inflammation in asthma. J Investig Med. 2010 Dec;58(8):987-90.

[11]Pitchford SC, Momi S, Giannini S, Casali L, Spina D, Page CP, Gresele P. Platelet P-selectin is required for pulmonary eosinophil and lymphocyte recruitment in a murine model of allergic inflammation. Blood. 2005;105(5):2074- 2081.

[12]Brims FJ, Chauhan AJ, Higgins B, Shute JK. Up-regulation of the extrinsic coagulation pathway in acute asthma--a case study. J Asthma. 2010 Aug;47(6):695-8.

[13]Brims FJ, Chauhan AJ, Higgins B, Shute JK. Coagulation factors in the airways in moderate and severe asthma and the effect of inhaled steroids. Thorax 2009;64:1037-1043 
[14]Shanley LA, Lin H, Flores G. Factors associated with length of stay for pediatric asthma hospitalizations. J Asthma. 2014 Nov 21:1-7

[15]Davis SR, Burke G, Hogan E, Smith SR . Corticosteroid timing and length of stay for children with asthma in the Emergency Department. J Asthma. 2012 Oct;49(8):862-7

[16]Gibbison B, Griggs K, Mukherjee M, Sheikh A. Ten years of asthma admissions to adult critical care units in England and Wales. BMJ Open. 2013 Sep 19;3(9):e003420

[17]Soyiri IN, Reidpath DD, Sarran C. Asthma Length of Stay in Hospitals in London 2001-2006: Demographic, Diagnostic and Temporal Factors. PLoS ONE 6(11): e27184.

[18]Oliver JA, Monroe DM, Roberts HR, Hoffman M. Thrombin activates factor XI on activated platelets in the absence of factor XII. Arterioscler Thromb Vasc Biol. 1999 Jan;19(1):170-7.

[19] Korte W, Clarke S, Lefkowitz JB. Short activated partial thromboplastin times are related to increased thrombin generation and an increased risk for thromboembolism. Am J Clin Pathol. 2000 Jan;113(1):123-7.

[20]Majoor CJ, van de Pol MA, Kamphuisen PW, Meijers JC, Molenkamp R, Wolthers KC, van der Poll T, Nieuwland R, Johnston SL, Sterk PJ, Bel EH, Lutter R, van der Sluijs KF. Evaluation of coagulation activation after rhinovirus infection in patients with asthma and healthy control subjects: an observational study. Respir Res. 2014 Feb 7;15:14

[21]El-Shaboury AH, Thomas AJ, Williams DA. Serum Transaminase Activity in Status Asthmaticus. Br Med J. 1964 May 9;1(5392):1220-3

[22]Athie-Morales V, Smits HH, Cantrell DA, Hilkens CM. Sustained IL-12 signalling is required for Th1 development. J Immunol. 2004 Jan 1;172(1):61-9.

[23]Naseer T, Minshall EM, Leung DY, Laberge S, Ernst P, Martin RJ, Hamid Q. Expression of IL-12 and IL-13 mRNA in asthma and their modulation in response to steroid therapy. Am J Respir Crit Care Med. 1997 Mar;155(3):845-51.

[24]Basalingappa D, Sandhya M, Satyanarayana U, Mohanty S. Impact of chronic cigarette smoking on platelet aggregation and coagulation profile in apparently healthy male smokers. Int. J. Clin. Exp. Physiol. 2015 June; 2(2): 128-133 


\begin{tabular}{|l|l|}
\hline Table 1. Participant characteristics & Mean ( \pm Standard Deviation) \\
\hline Gender & 94 female $(75.25 \%), 32$ male (24.75\%) \\
\hline Age (years) & $39.9( \pm 14.3)$ \\
\hline BMI (Kg/m ${ }^{2}$ ) & $30.7( \pm 7.96)$ \\
\hline Inhaled corticosteroid dose ( $\mu$ Bg BD equivalent) & $1056( \pm 964)$ \\
\hline Length of stay (days) & $3.93( \pm 2.64)$ \\
\hline FEV1 (\% predicted) & $65.2( \pm 23.9)$ \\
\hline Fractional exhaled nitric oxide (parts per billion) & $42.9( \pm 39.7)$ \\
\hline Smoking History (pack years) & $3.47( \pm 5.51)$ \\
\hline Delay between symptom onset and attendance (days) & $5.4( \pm 15.9)$ \\
\hline
\end{tabular}

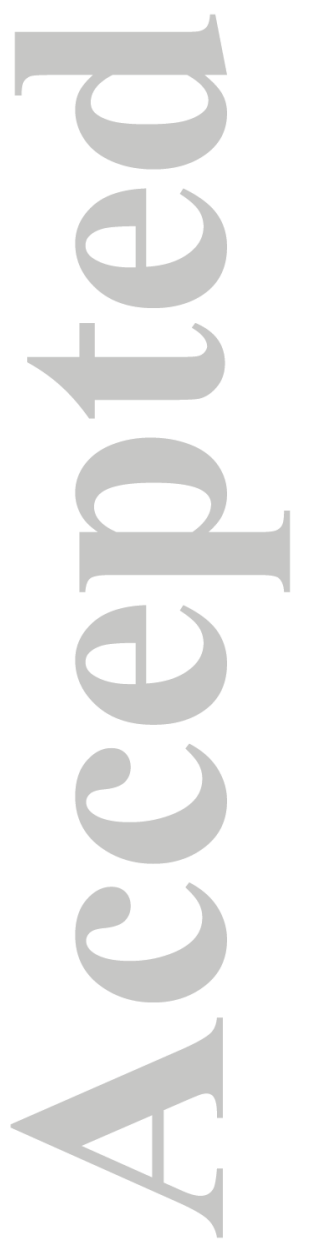

This article is protected by copyright. All rights reserved. 


\begin{tabular}{|c|c|c|c|c|}
\hline Variable & $\mathbf{N}$ & Category & Ratio (95\% Cl) & P-value \\
\hline Age (Years) †‡ & 125 & & $1.08(1.02,1.15)$ & 0.003 \\
\hline Baseline ICS dose & 118 & $\begin{array}{l}\text { Low }(<800 \mu \mathrm{g} \text { BDP }) \\
\text { Moderate }(800<1600 \mu \mathrm{g} \text { BDP }) \\
\text { High }(\geq 1600 \mu \mathrm{g} \text { or oral steroid) }\end{array}$ & $\begin{array}{c}1 \\
0.91(0.66,1.26) \\
0.98(0.72,1.33) \\
\end{array}$ & 0.84 \\
\hline $\begin{array}{l}\text { Delay between symptom } \\
\text { onset and attendance }\end{array}$ & 121 & $\begin{array}{l}0-1 \text { days } \\
2-7 \text { days } \\
8+\text { days }\end{array}$ & $\begin{array}{c}1 \\
0.93(0.71,1.22) \\
1.45(0.96,2.19) \\
\end{array}$ & 0.10 \\
\hline APTT ratio $\S$ & 118 & - & $0.84(0.75,0.94)$ & 0.003 \\
\hline INR § & 121 & - & $0.99(0.85,1.15)$ & 0.87 \\
\hline AST (IU/L) ๆ & 118 & - & $1.05(1.00,1.11)$ & 0.04 \\
\hline IL-5 (pg/mL) ף & 61 & - & $1.05(0.94,1.16)$ & 0.37 \\
\hline IL-6 (pg/mL) & 61 & $\begin{array}{l}<0.5 \\
0.5-3 \\
>3\end{array}$ & $\begin{array}{c}1 \\
0.91(0.59,1.61) \\
1.23(0.75,2.02) \\
\end{array}$ & 0.6 \\
\hline IL-12 (pg/mL) & 61 & $\begin{array}{c}0 \\
1-50 \\
>50\end{array}$ & $\begin{array}{c}1 \\
1.41(0.88,2.23) \\
1.56(0.92,2.65) \\
\end{array}$ & 0.19 \\
\hline $\begin{array}{l}\text { Participant-reported } \\
\text { wheeze }\end{array}$ & 125 & $\begin{array}{l}\text { No } \\
\text { Yes }\end{array}$ & $\begin{array}{c}1 \\
1.88(1.20,2.94)\end{array}$ & 0.006 \\
\hline Admission FiO2 (\%) & 99 & $\begin{array}{c}21 \% \\
>21 \%\end{array}$ & $\begin{array}{c}1 \\
1.72(1.15,2.57)\end{array}$ & 0.009 \\
\hline FEV1 (L) & 122 & - & $0.79(0.67,0.93)$ & 0.005 \\
\hline FVC $(\mathrm{L})$ & 122 & - & $0.86(0.76,0.98)$ & 0.02 \\
\hline$\%$ predicted $\mathrm{FEV}_{1}{ }^{\dagger}$ & 122 & - & $0.96(0.91,1.02)$ & 0.16 \\
\hline \multicolumn{5}{|c|}{$\begin{array}{l}\text { + Ratios reported for a } 10 \text { unit increase in age and \%predicted FEV } \\
\text { ‡ Squared term } \\
\text { § Ratios reported for a 0.1-unit increase in APTT ratio and INR } \\
\text { 9 Ratios reported for a 5-unit increase in IL-5 and AST }\end{array}$} \\
\hline
\end{tabular}




\begin{tabular}{|c|c|c|c|}
\hline \multicolumn{4}{|c|}{ Table 3 - Multivariable length of stay analysis } \\
\hline Variable & Category & Ratio (95\% Cl) & P-value \\
\hline Age (years) †‡ & - & $1.09(1.02,1.16)$ & 0.02 \\
\hline APTT ratio $\S$ & - & $0.77(0.68,0.88)$ & $<0.001$ \\
\hline $\operatorname{AST}(I U / L)$ ף & - & $1.08(1.02,1.13)$ & 0.005 \\
\hline$\%$ of predicted FEV + & - & $0.93(0.88,0.99)$ & 0.02 \\
\hline \multirow{2}{*}{$\mathrm{FiO} 2(\%)$} & $21 \%$ & 1 & \multirow{2}{*}{0.02} \\
\hline & $>21 \%$ & $1.57(1.09,2.25)$ & \\
\hline \multicolumn{4}{|c|}{$\begin{array}{l}\text { + Ratios reported for a } 10 \text { unit increase in age and \%predicted FEV1 } \\
\text { ₹ Squared term } \\
\S \text { Ratios reported for a } 0.1 \text {-unit increase in APTT ratio }\end{array}$} \\
\hline
\end{tabular}
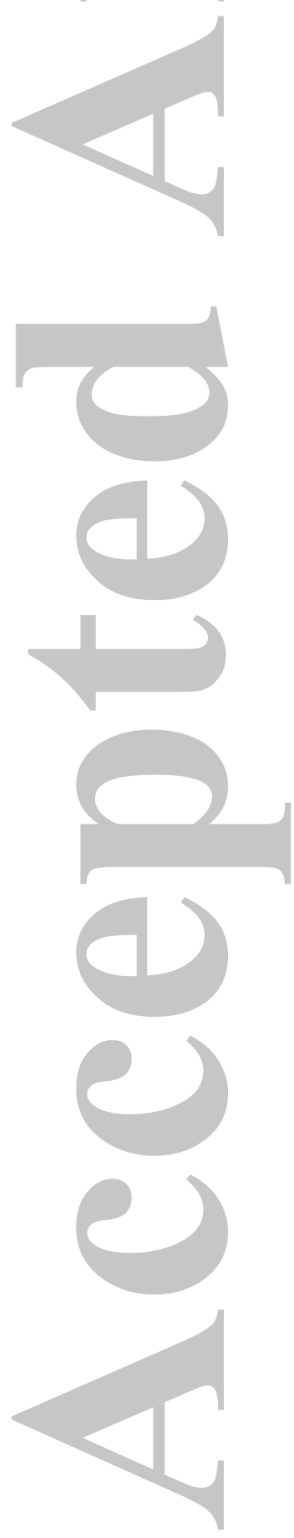

This article is protected by copyright. All rights reserved. 


\begin{tabular}{|c|c|c|c|c|}
\hline Variable & $\mathbf{N}$ & Category & Hazard Ratio $(95 \% \mathrm{Cl})$ & P-value \\
\hline Age(Years) ${ }^{\dagger}$ & 98 & - & $1.01(0.87,1.18)$ & 0.89 \\
\hline $\begin{array}{c}\text { Baseline ICS dose (BDP } \\
\text { equivalents) }\end{array}$ & 93 & $\begin{array}{c}\text { Low }(<800 \mu \mathrm{g}) \\
\text { Moderate } \\
(800<1600 \mu \mathrm{g}) \\
\text { High }(\geq 1600 \mu \mathrm{g} \text { or } \\
\text { oral steroid) }\end{array}$ & $\begin{array}{c}1 \\
0.69(0.38,1.26) \\
0.91(0.52,1.58)\end{array}$ & 0.46 \\
\hline $\begin{array}{l}\text { Delay from symptom } \\
\text { onset to admission }\end{array}$ & 95 & $\begin{array}{l}0-1 \text { days } \\
2-7 \text { days } \\
8+\text { days }\end{array}$ & $\begin{array}{c}1 \\
0.78(0.47,1.29) \\
0.65(0.29,1.43)\end{array}$ & 0.46 \\
\hline Length of stay (days) & 98 & - & $0.91(0.83,1.00)$ & 0.06 \\
\hline Reliever use (uses/day) ๆ & 94 & - & $0.96(0.89,1.02)$ & 0.18 \\
\hline Family history asthma & 86 & $\begin{array}{l}\text { No } \\
\text { Yes }\end{array}$ & $\begin{array}{c}1 \\
0.49(0.30,0.80)\end{array}$ & $\underline{0.005}$ \\
\hline APTT Ratio $\S$ & 92 & - & $1.02(0.84,1.25)$ & 0.83 \\
\hline INR § & 95 & - & $0.82(0.62,1.09)$ & 0.18 \\
\hline $\mathrm{IL}-5(\mathrm{pg} / \mathrm{mL})$ ๆ & 60 & - & $1.01(0.87,1.18)$ & 0.88 \\
\hline $\mathrm{IL}-12(\mathrm{pg} / \mathrm{mL})$ & 60 & $\begin{array}{c}0 \\
1-50 \\
>50\end{array}$ & $\begin{array}{c}1 \\
0.44(0.23,0.84) \\
0.52(0.24,1.11)\end{array}$ & $\underline{0.04}$ \\
\hline TNF- $\alpha(\mathrm{pg} / \mathrm{mL})$ q & 60 & - & $0.90(0.71,1.13)$ & 0.35 \\
\hline \multicolumn{5}{|c|}{$\begin{array}{l}\text { (†) Ratios reported for a } 10 \text { year increase in age } \\
\text { (१) Ratios reported for a 5-unit increase in Reliever use, TNF- } \alpha \text { and IL-5 } \\
\text { (§) Ratios reported for a 0.1-unit increase in APTT ratio and INR }\end{array}$} \\
\hline
\end{tabular}




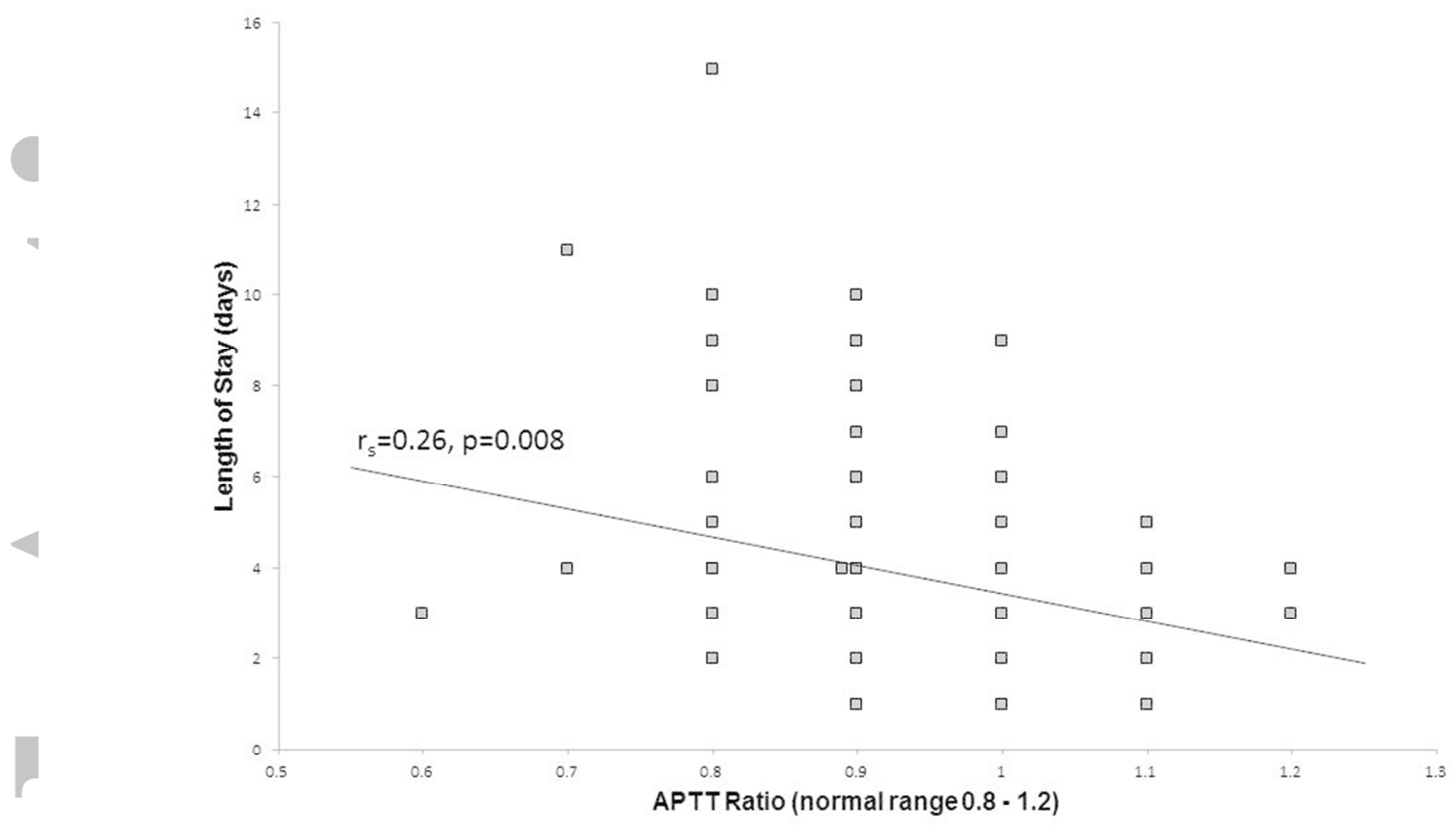

Figure 1. Length of stay negatively correlates with APTT ratio, with the majority of the variation occurring in the normal range of $0.8-1.2$.

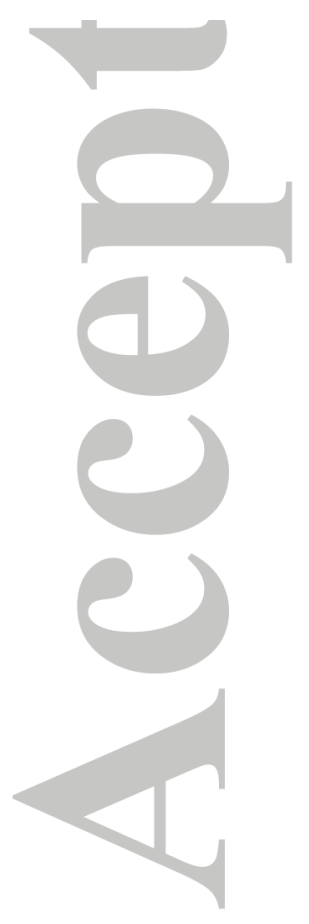
$254 \times 190 \mathrm{~mm}$ (96 x 96 DPI) 


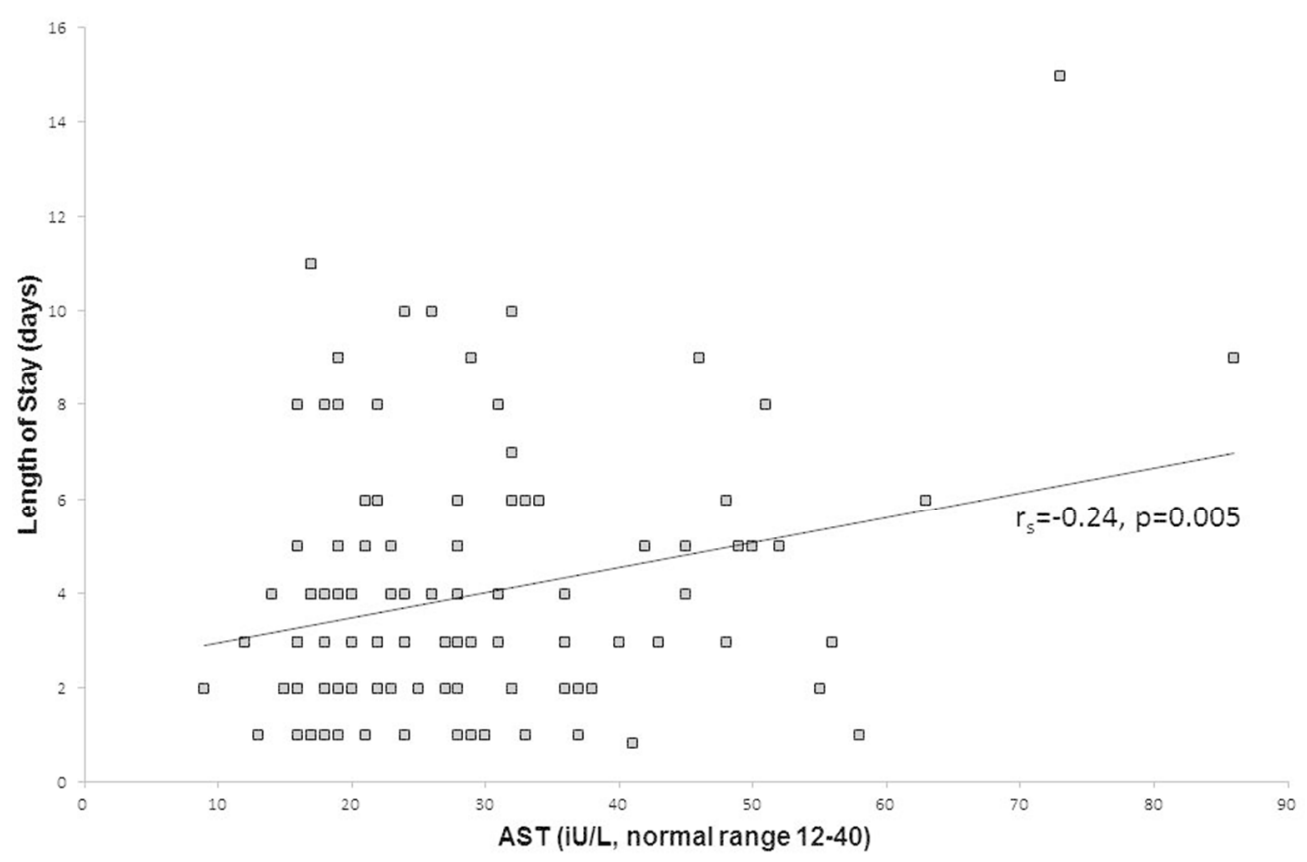

Figure 2. Length of stay correlates with serum Aspartate Transaminase concentrations. $254 \times 190 \mathrm{~mm}(96 \times 96 \mathrm{DPI})$

This article is protected by copyright. All rights reserved. 


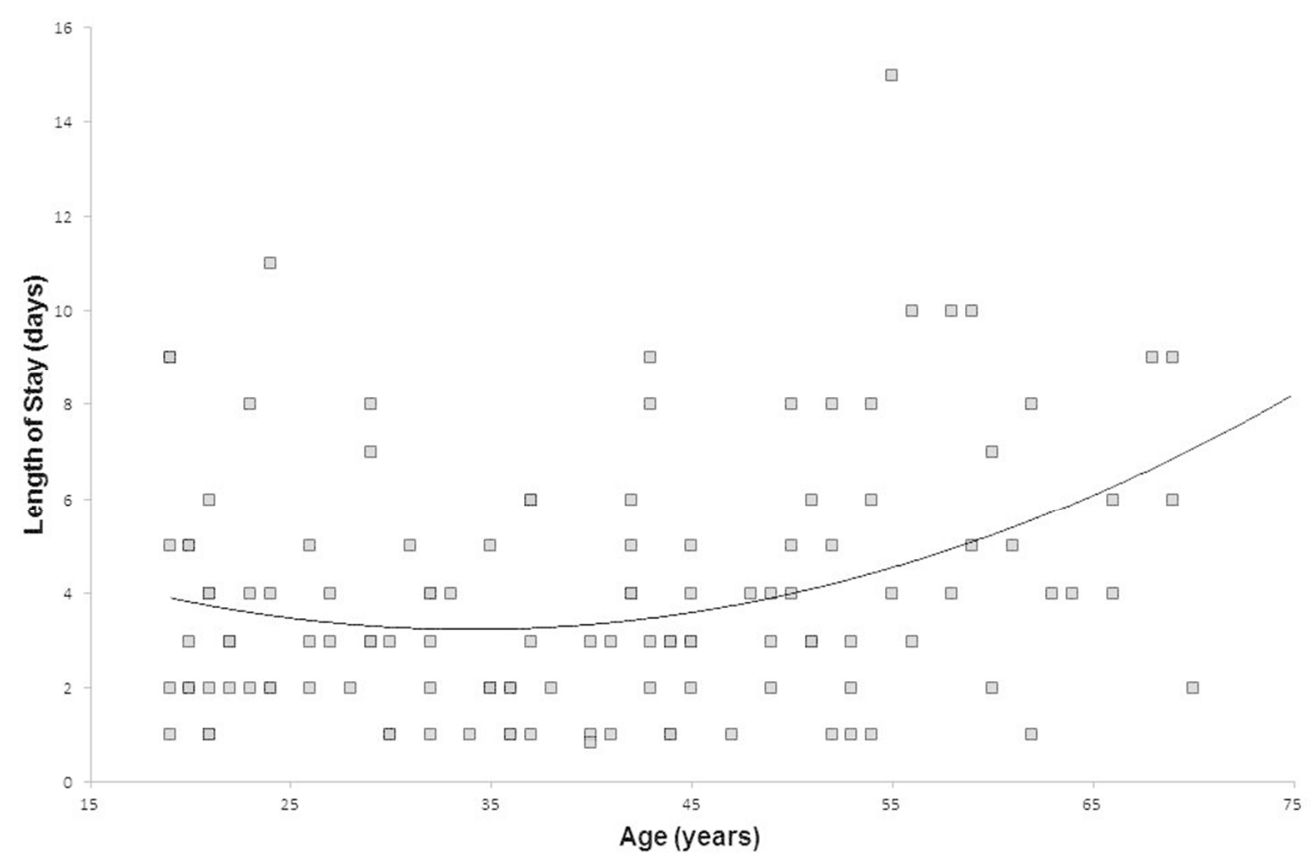

Figure 3. Length of stay correlates non-linearly with age, with a rapid increase in length of stay over the age of 50 years.

$254 \times 190 \mathrm{~mm}(96 \times 96 \mathrm{DPI})$

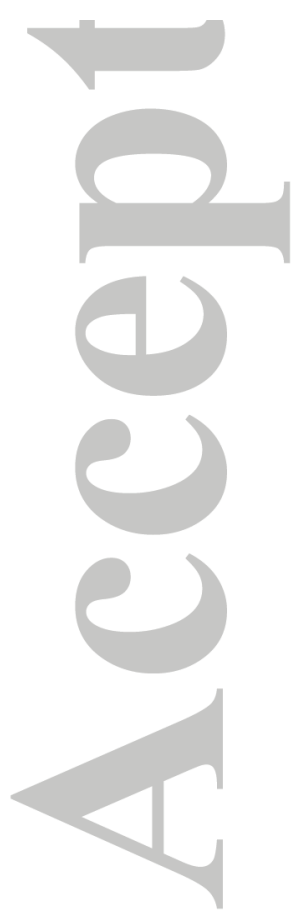

This article is protected by copyright. All rights reserved. 